M. Łyskowski, E. Mazurek, and J. Ziętek - Ground Penerating Radar investigation of limestone karst at the Odstrzelona Cave in Kowala, Świętokrzyskie Mountains, Poland. Journal of Cave and Karst Studies, v. 76, no. 3, p. 184-190. DOI: 10.4311/2014EX0001

\title{
GROUND PENERATING RADAR INVESTIGATION OF LIMESTONE KARST AT THE ODSTRZELONA CAVE IN KOWALA, ŚWIĘTOKRZYSKIE MOUNTAINS, POLAND
}

Mikolaj Łyskowski, Ewelina Mazurek, And Jerzy Ziętek

AGH University of Science and Technology, Faculty of Geology, Geophysics and Environmental Protection, A. Mickiewicza 30 Ave., 30-059 Krakow, Poland, lyskowski@geol.agh.edu.pl

\begin{abstract}
Ground Penetrating Radar (GPR) is one of the most effective and rapid types of geophysical surveys methods. The variety of its uses is limited only by the availability of components such as antennas with different frequencies of emitted radio waves. The application of GPR ranges from engineering applications and geological investigations to assessing the condition of old trees. The authors tested GPR measurements in a geological exploration of a newly discovered limestone cave in the Świętokrzyskie Mountains region, the Odstrzelona Cave in Kowala, near the village of that name. Investigations were ordered by the municipality of Sitkówka-Nowiny, in the Świętokrzyskie district in Poland. GPR surveys were conducted in the vicinity of a known cave entrance to see if information could be gained on nearby karst features. GPR investigations documented two additional chambers and a few more openings in the limestone. Unfortunately, they are probably too small to explore.
\end{abstract}

\section{INTRODUCTION}

Ground Penetrating Radar (GPR) is a fast geophysical method that allows precise and effective recognition of geological formations below the surface. Dry or moderately wet solid rocks are the best medium for such a survey. Review of the available literature shows that the GPR method is a good geophysical tool for detecting karst phenomena and caves. Doolittle and Collins (1998) compared the electromagnetic induction method to GPR results and obtained very good results. Chamberlain et al. (2000) gave examples of cave detection in limestones. Their surveys gave good results and thanks to a grid of parallel profiles, it was possible to present them in different ways, as both classical profiles and time slices. Another example of the application of the GPR method in detecting caves is presented by Beres et al. (2001), in which the GPR method was compared to microgravimetric measurements. The obtained results are good examples of GPR profiles. Anomalies in GPR echograms were confirmed by the gravity measurement results.

Investigations carried out by the authors and presented in this paper were focused on a cave newly rediscovered in 2008 near the city of Kielce, central Poland, and on detecting karst phenomena. The cave was probably discovered many years before during exploration work performed by the workers of the quarry Stara Trzuskawica, who shot away the ceiling in the entrance tunnel of the cave. For safety reasons, in the 1970s the cave was drilled and filled with limestone rubble made from surrounding rocks (Grzelak, 2012). As a result, the cave was unavailable for many years following the closure of the quarry. Speleologists who investigated the quarry named it Odstrzelona Cave in Kowala (Polish word odstrzelona means shoot away; Kowala is the village where the cave is located). After the discovery of the entrance, they wanted to seek karst areas adjacent to the cave. Speleologists proposed GPR measurements, because of previous experience with that method. Before the survey, researchers analyzed available geological information and made a local inspection to determine if use of GPR was feasible. The survey was done in November 2010. The data from the GPR measurements were processed and interpreted very carefully to provide a basis for future speleological investigations, as well as for evaluating risk to public safety. We have obtained results of a very good quality that allowed us to precisely locate karst objects in the limestone and the location of unknown chambers, voids, and cracks.

\section{Study AreA}

In terms of Polish geographical regions presented by Kondracki (2011), the area where the Odstrzelona Cave in Kowala is located belongs to the Kielce Upland macroregion located in central Poland. More precisely, it is the Świętokrzyskie (Holy Cross) Mountains mezzo-region and the Chęcińskie Hills micro-region. This area is composed of limestone and dolomite of the Middle Devonian period.

The cave is located in the closed quarry Stara Trzuskawica north of the village of Kowala in the municipality of Sitkówka-Nowiny. Rocks forming the walls of the cave are Devonian limestones. The origin of the cave is associated with a typical karst processes. The entrance is artificial, created during exploration work in the quarry. Only a small part of the cave is accessible. Access to the rest of the cave is not possible because of the collapse of ceiling and walls, which took place after the blasting at the quarry. The collapsed tunnels are filled with 


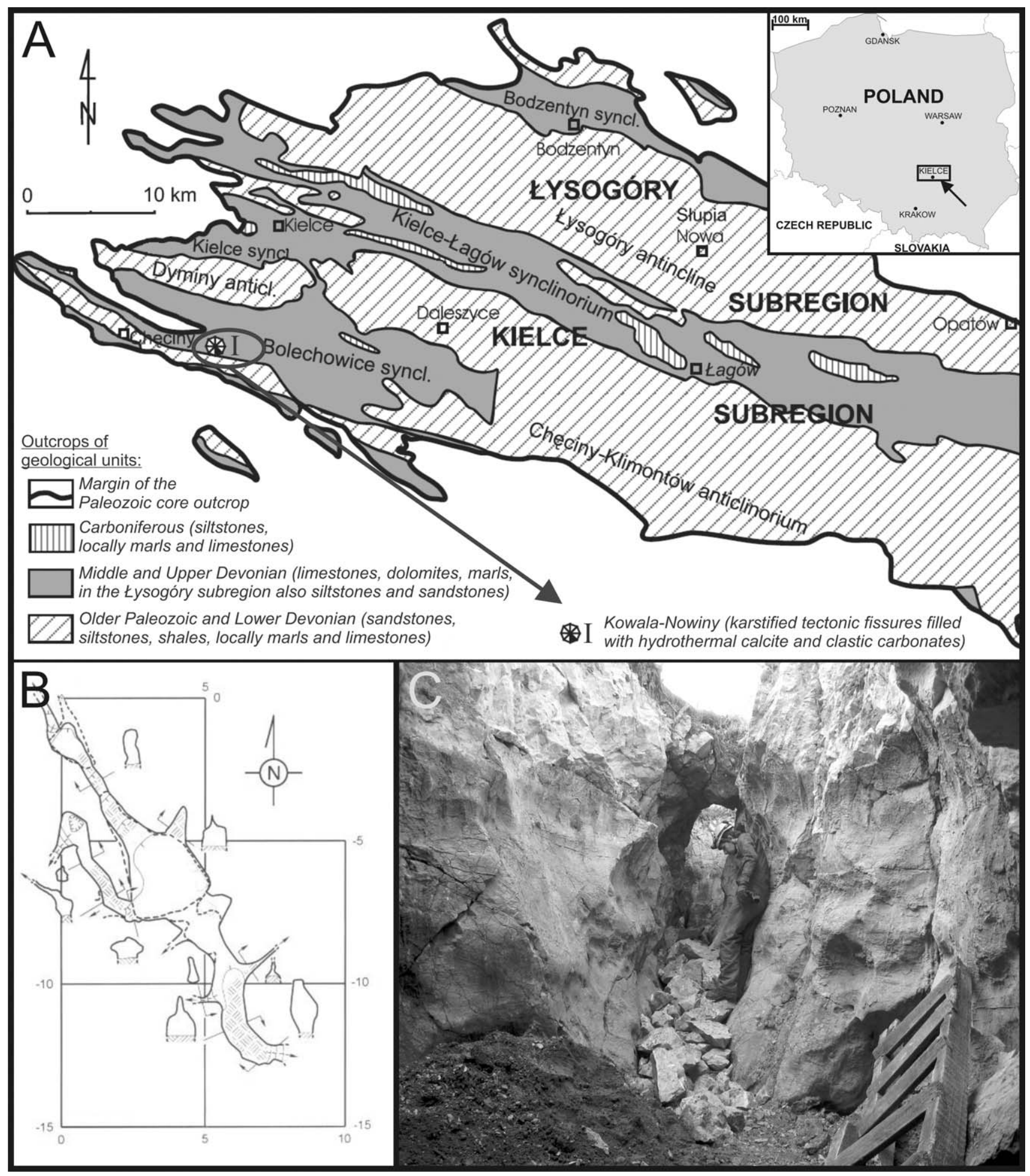

Figure 1. A-Geological map of the Świętokrzyskie (Holy Cross) Mountains mezzo-region, with inset showing its location in Poland (modified from Urban, 2007). B-A surface geological map of the Odstrzelona Cave in Kowala (Grzelak, 2012). CPhoto from inside of the cave taken by Mr. Maciej Grzelak.

limestone rubble. The open part has been explored and has a length of $28.8 \mathrm{~m}$ and a height reaching $3.8 \mathrm{~m}$ (Grzelak, 2012). Figure 1 shows the location of the cave and the surrounding geology.
Because of terrain topography typical of an opencast quarry, it was not possible to conduct measurements in a parallel grid. Surveys had to be carried out along specially cut paths in the vegetation surrounding the area. Additional 
Ground Penerating Radar investigation of limestone karst at the Odstrzelona Cave in Kowala, Świętokrzyskie Mountains, Poland

problems were caused by the multiple levels of the closed quarry. The direction and location of GPR profiles was determined by the local speleologists who had rediscovered the cave. Cut paths were made in places interesting for them and where they predicted continuation of the karst cave. The GPR profiles are shown in Figure 2.

\section{BASICS OF GPR SURVEY}

A GPR system includes central processing unit, signal generator, transmitter, transmitting and receiving antennas, receiver, and measuring gear. Today's systems have an onboard laptop computer that facilitates data acquisition and pre-processing in the field (Reynolds, 1997). The modern system uses the bistatic type of antennas in which two separate antennas are used, with one serving as a transmitter and the other as a receiver (Annan, 2001). The GPR systems produced today use antennas with frequencies from $10 \mathrm{MHz}$ to $6000 \mathrm{MHz}$ (British custom GPR system Groundvue 5C). Based on their structure, bistatic antennas can be divided into the two most commonly used types, shielded and unshielded. In the case of the first type, transmitting and receiving antennas are encased in an electromagnetic shield. The housing makes them less prone to external interference, such as reflections from trees, and is also designed for aiming the electromagnetic (EM) wave directly into the medium. Unshielded antennas are not shielded from the interference and are not physically integrated. Separation of transmitting and receiving antennas makes it possible to carry out investigations with different spacing distances between the dipoles and with different polarizations of the dipoles in relation to the profile line. Unshielded antennas also allow the special kind of survey called WARR profiling (Wide-Angle Reflection and Refraction, the final result of which is an echogram that is used for determination of the EM wave propagation velocity in the medium (Lyskowski and Mazurek, 2013)).

The GPR system is based on a transmitter generating a pulse of radio waves at a frequency determined by the characteristics of the antennas. EM waves are emitted from a source to detect an object at a distance and determine the direction to the object as well as the distance to the object. In order for an object to reflect radio waves it must have different dielectric properties from the surrounding material, referred to as the medium (Annan, 2001). Emitted radio waves travel at a speed that depends on the material in which they propagate. Each scan lasts as long as the total two-way travel time range. This value, defined as the time window, can be set by the operator from a few tens to several thousands of nanoseconds (Reynolds, 1997).

The electromagnetic characteristics of materials are related to their composition and water saturation. Due to the high frequency of radar waves, they are sensitive to both changes in conductivity and dielectric properties of materials, which affect the speed of radio-wave propagation and the attenuation of electromagnetic waves in the medium (Reynolds, 1997).

Wave attenuation determines the depth range of GPR method. Wave attenuation means the gradual reduction of an electromagnetic pulse's amplitude along the travel path. It depends on four basic factors, the geometrical divergence of the wave front from the point source of the wave, scattering related to nonhomogeneity of the medium, propagation dispersion of the waves, which depends on frequency, and the electrical conductivity of the medium, usually mainly due to pore fluids (Annan, 2001).

The frequency of the signal emitted by the antennas also defines the depth range and the resolution. The lower the frequency of emitted EM wave, the greater the depth penetration, but the lower resolution of the survey. On the other hand, with increasing frequency, the resolution is higher, but the range decreases.

For the GPR method, the concept of resolution is important, but quite complex. We can define vertical and horizontal resolutions. The simplest definition of both resolutions says that it is the minimum distance between two objects with the same cross section that are visible on the echogram as separate anomalies (Annan, 2001).

\section{Methods}

The GPR surveys presented in this paper were obtained using a ProEx GPR unit (MALA Geoscience, Sweden) with a $250 \mathrm{MHz}$ shielded antenna. This equipment allowed the acquisition of information to a theoretical depth range of about $13 \mathrm{~m}$. Test measurements with a $100 \mathrm{MHz}$ unshielded antenna were done along a single profile, profile 16, that was located above the cave. The obtained depth penetration reached about $18 \mathrm{~m}$. The whole case study consists of sixteen profiles. Their courses and locations are presented in Figure 2 on a schematic map of the survey site, along with sample echograms.

The echogram is a final result of the GPR survey. It is composed of the traces that register the reflected EM wave amplitudes as a function of time. The traces are arranged one by one along the $\mathrm{X}$-axis. The length of the profile is calculated by the computer by revolving the measuring gear connected to the antennas. These mechanisms can generate small errors in determining the profile length. Despite the fact that the measurement is done in steps declared in centimeters, it is called continuous.

Raw data collected from the GPR surveys were recorded in nanoseconds. To obtain the vertical axis of the echograms as a depth scale in meters, it was necessary to do a time-to-depth conversion. This process needs the value of EM wave velocity in the medium, which can be obtained from WARR profiling. The velocity can be also calculated from the relative dielectric constant $\left(\varepsilon_{\mathrm{r}}\right)$ taken from published data (e.g. Reynolds, 1997, p. 682-749; OYO, 1988; MALÅ, 2009). To do so, the EM wave velocity is given by the speed of light in vacuum, $0.3 \mathrm{~m} \mathrm{~ns}^{-1}$, 


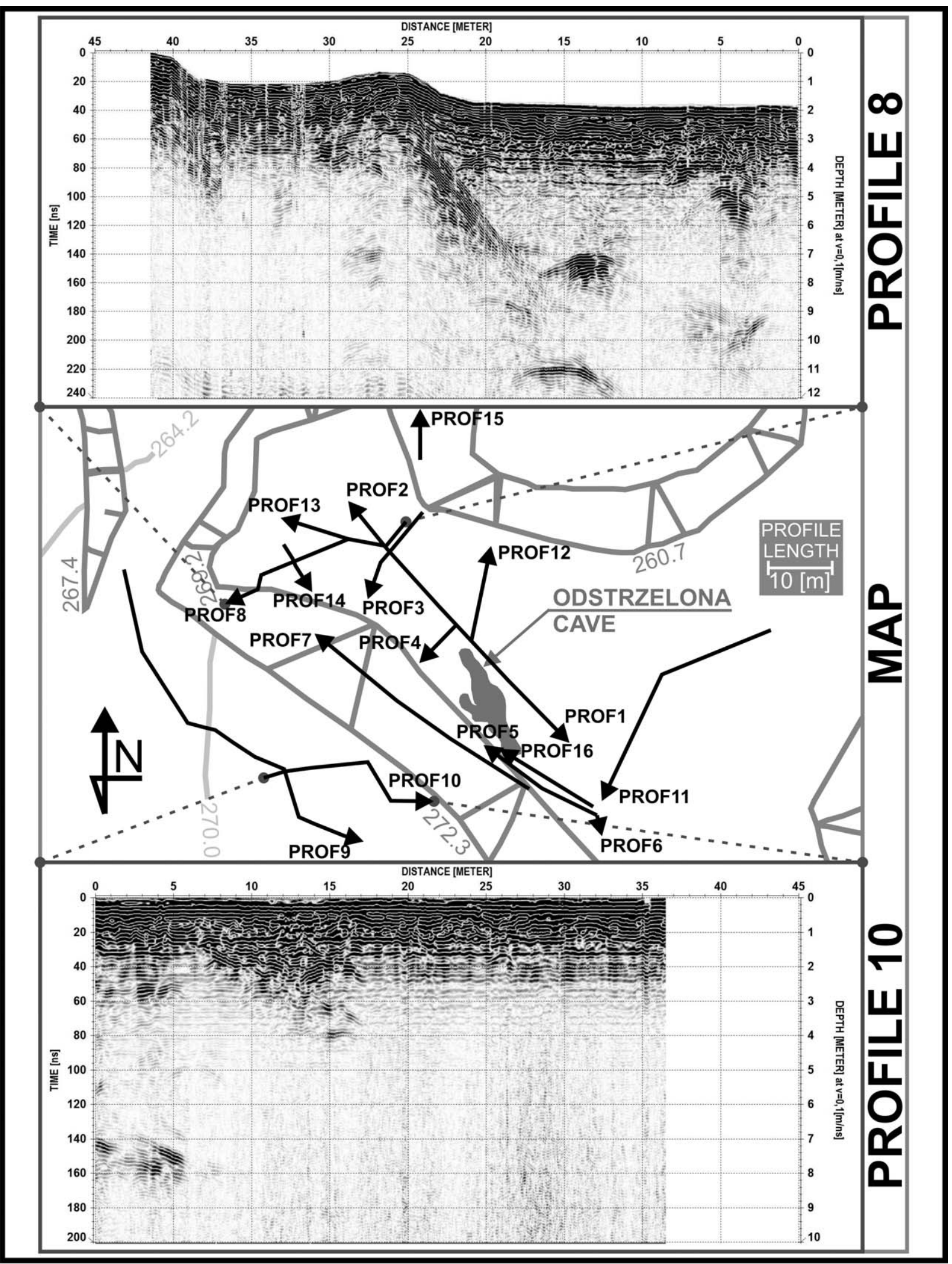

Figure 2. Schematic geographical map of survey site containing position and course of GPR profiles (black lines with arrows) and the location of Odstrzelona Cave in Kowala (center); Two echograms, from profiles 8 and 10, with visible anomalies from karst features. Note that the distance scale along the profiles in the top echogram is backwards. Light gray lines are isolines (elevation), and dark gray lines are contours of the excavation in the quarry Stara Trzuskawica. 
Ground Penerating Radar investigation of limestone karst at the Odstrzelona Cave in Kowala, Świętokrzyskie Mountains, Poland

divided by the square root of the relative dielectric constant of the medium (Karczewski et al., 2011). Due to the topography of the terrain and the vegetation, the authors determined the velocity by using an estimation from a table.

\section{Data Processing and Results}

The raw data were processed using the software ReflexW (Sandmeier Scientific Software). Data-processing work-flow included noise removal, frequency filtering, gaining, and smoothing. It is also possible to apply an approximate topographic shape of the area (profile 8 in Figure 2). The data presented in this paper were processed as follows, using the procedure names in the program (ReflexW, 2009): "move starttime" accepts a fixed value in nanoseconds that is the time of the first signal in the echogram. "subtract-DC-shift" calculates the mean value of the trace (the "DC value") for the given time range and subtracts this value from all data. "substract-mean (dewow)" creates a moving time window along the $\mathrm{Z}$ axis, subtracting the mean values from the actual data. "bandpassbutterworth" performs bandbass frequency filtering in the time domain of each trace. "time cut" removes trace values below a specified time value. "gain function" strengthens reflections with a time-dependent multiplier. "average xy-filter" is a smoothing filter that calculates the average for a specified data range. And "static correction," applied only to profile 8 in Figure 2, applies surface topography to the echogram.

The data-processing work-flow presented above was chosen as the most effective from several that have been tried. Time-depth conversion of the GPR data was done with the use of published data for the relative dielectric constant of limestone. The assumed value $\varepsilon_{\mathrm{r}}=9$ corresponds to electrical conductivity of medium-wet limestone (OYO, 1988). It gives an EM wave velocity calculated as $v=0.1 \mathrm{~m} \mathrm{~ns}^{-1}$. The conversion from nanoseconds to meters depth is then a factor of 20 , since the echo has traveled both ways.

Profile 8 shown in Figure 2 contains information about the topography. Please notice that the horizontal axis in this plot is in inverse order. The visible dipping reflections, which start from $25 \mathrm{~m}$ along the profile (below abbreviated $\mathrm{r}-\mathrm{m}$, for running meters), can be assigned to the geological layers of limestones or karst fissures. Between 11 and $17 \mathrm{r}$ $\mathrm{m}$ there are two anomalies at the depth of 7 and $10.5 \mathrm{~m}$ that could originate from karst voids. At about $4 \mathrm{r}-\mathrm{m}$ at the depth of $4 \mathrm{~m}$, the anomaly of a void is clearly visible, and another one that could be induced by deep cracks in the limestone, is visible at a depth of $9 \mathrm{~m}$.

At the beginning of profile 10 there is a visible anomaly for a karst cave, which corresponds to the one visible on profile 9 in Figure 3 at $30 \mathrm{r}-\mathrm{m}$. Between 10 and $17 \mathrm{r}-\mathrm{m}$ at the depth of about 1 to $4 \mathrm{~m}$ we can see an anomaly from loose rock.
Profile 2, shown in Figure 3, is the closest one to the Odstrzelona Cave in Kowala and shows a crack located near the opened fragment of the cave. The whole series of small hyperbolas between 5 and $35 \mathrm{r}-\mathrm{m}$ of the profile, starting at the depth of $1 \mathrm{~m}$, are the result of karst processes. The anomaly at $45 \mathrm{r}-\mathrm{m}$ at the depth of $6 \mathrm{~m}$ and thickness of about $1 \mathrm{~m}$ can be assigned to a karst void, as can be the anomaly less visible at a depth about $8.5 \mathrm{~m}$.

A distinct anomaly from a karst void appears on profile 3 (Fig. 3) at $10 \mathrm{r}-\mathrm{m}$ and a depth of $6.5 \mathrm{~m}$. Underneath we can see poorly visible anomalies from cracks in the old quarry. Near $5 \mathrm{r}-\mathrm{m}$ at the depth of $2 \mathrm{~m}$ a small anomaly can be seen, which probably is also associated with karst processes. At $14 \mathrm{r}-\mathrm{m}$ of the profile one more anomaly, elongated in time with height of about $8 \mathrm{~m}$, can be observed. We suggest that it originated from a karst chimney.

Profile 12 (Fig. 3) was designed in order to see if Odstrzelona Cave in Kowala continues to the north. In the first $10 \mathrm{r}-\mathrm{m}$ of the profile there are many anomalies related to cracks near the opened fragment of cave. From about 12 $\mathrm{r}-\mathrm{m}$ at about 1 to $3.5 \mathrm{~m}$ depth, an anomaly with a similar origin appears.

The very interesting profile 9 (Fig. 3) shows without doubt four big and clearly visible anomalies. They are pictures of a karst cave with two chambers. The first one starts at $23 \mathrm{r}-\mathrm{m}$ of profile and continues for the next $11 \mathrm{r}-\mathrm{m}$, until $34 \mathrm{r}-\mathrm{m}$. The second one can be found at $52 \mathrm{r}-\mathrm{m}$ and is visible for $10 \mathrm{~m}$. Their ceilings start at depths $3.5 \mathrm{~m}$ for the first one and $3 \mathrm{~m}$ for the second one. Measured thickness reaches up to $2.5 \mathrm{~m}$. Bright anomalies below these two, at a depth of about 7.5 to $8 \mathrm{~m}$ and located at $25-40 \mathrm{r}-\mathrm{m}$ and 52 $62 \mathrm{r}-\mathrm{m}$, respectively, and thickness reaching up to $1.5 \mathrm{~m}$ are probably floors of these chambers. At the end of the profile we can see a similar anomaly to the one in profile 12 . The reflector, about 8-m high, is a karst chimney.

\section{Discussion And Conclusion}

Comparing the quality of obtained results to echograms from a study performed by Beres et al. (2001) shows our surveys to be equally satisfactory and precise.

Due to the limitations of GPR, there are several problems with conducting measurements and their interpretation. The survey has considerable space requirements. For carrying out GPR measurements, antennas need close or even direct contact with the bedrock surface. Trees and bushes, and even cut brush, are a great obstacle. Another limitation is the depth range and resolution. Those parameters are directly connected. For greater depth penetration, the resolution is lower and the size and weight of antennas grows; for example, an $800 \mathrm{MHz}$ shielded antenna has size approximately $0.4 \times 0.2 \mathrm{~m}$ and weighs $2.6 \mathrm{~kg}$, and a $250 \mathrm{MHz}$ shielded antenna is about $0.8 \times$ $0.5 \mathrm{~m}$ and $8 \mathrm{~kg}$. If you consider an ideal bedrock for GPR measurements, such as dry limestone, for reaching deeper it 


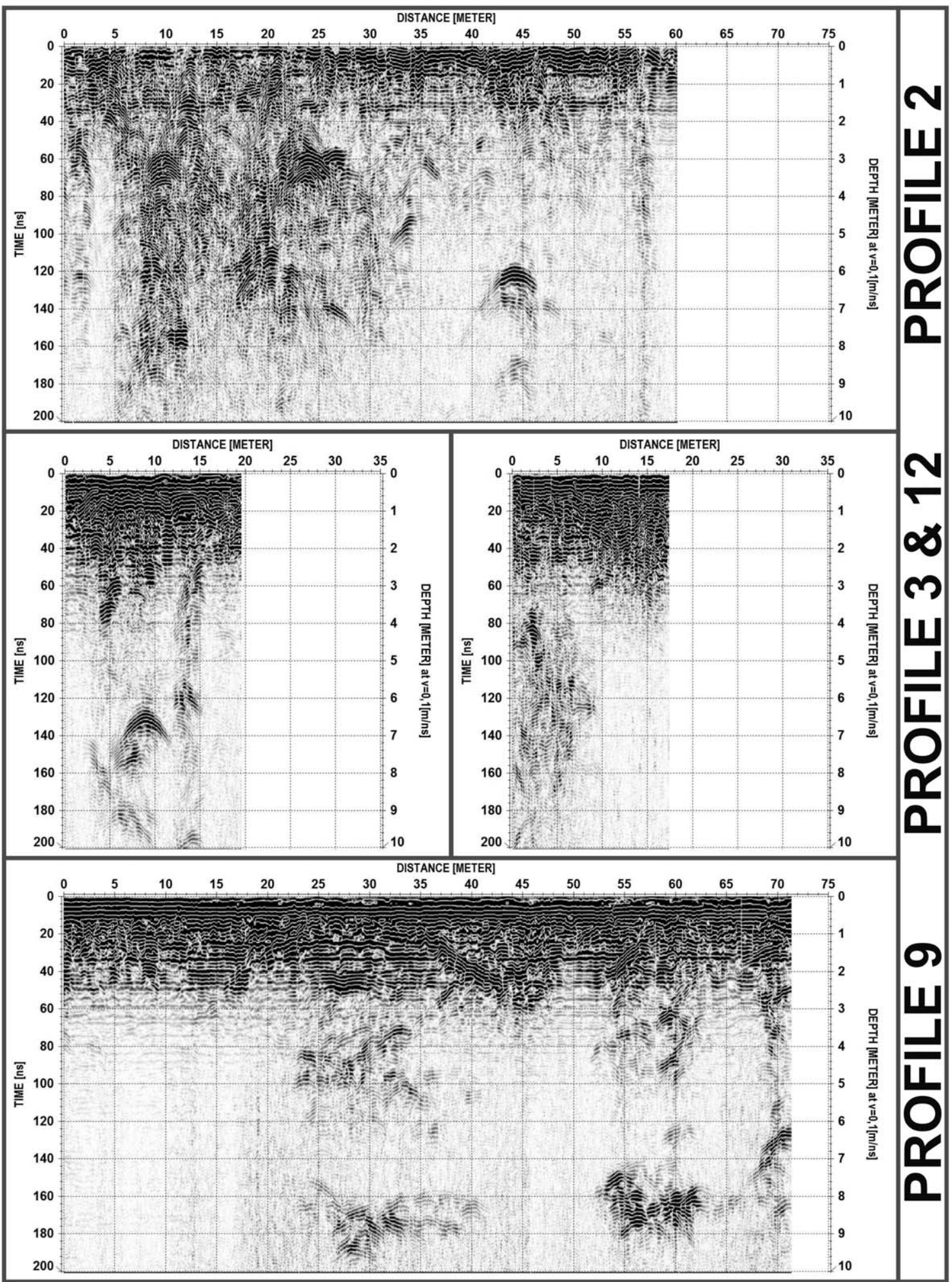

Figure 3. Echograms from profiles 2, 3, 9, and 12 containing clearly visible anomalies from karst process effects: disruption of the bedrock, as in profile 2 between 5 and $35 \mathrm{~m}$, or voids, as in profile 9, which has four large anomalies, two between 23 and $34 \mathrm{r}-\mathrm{w}$ and two between 52 and $62 \mathrm{r}-\mathrm{m}$, each pair interpreted as the ceiling and floor of a void. 
Ground Penerating Radar investigation of limestone karst at the Odstrzelona Cave in Kowala, Świetokrzyskie Mountains, Poland

is necessary to use a lower frequency, requiring a larger antenna and providing lower resolution. Use of a $250 \mathrm{MHz}$ antenna gave good-quality data and proved to be the right choice. The resolution and usable depth penetration range obtained, up to $10 \mathrm{~m}$, were satisfactory. The terrain covered with trees where the surveys were carried out also made that the choice of antenna frequency, size, and weight optimal. Usage of the shielded type antennas also reduced the noise, a source of which can be trees, so-called reflections in air. Before analyzing the results the authors repeatedly processed the raw data. The optimal sequence of processing was applied to all profiles. Processing all data in the same way guarantees confidence of interpretation. Only profile number 16 , because of the use of an unshielded $100 \mathrm{MHz}$ antenna, was processed individually. The procedures used removed unwanted noise and kept the interference in the raw data at a minimum.

Satisfactory detection of voids and cracks (e.g., Xu et al., 2010), caves, or karst objects is possible by using only GPR. There are many published examples of such exploratory works (e.g., Chamberlain et al., 2000). For the purposes of a full inventory of a cave it is necessary to perform a comprehensive study, including the use of other geophysical methods and a precise geodetic grid. Unfortunately, the topography and the dense forest of the old quarry made it impossible to conduct such a survey. Complementary use of other methods such as microgravity (Beres et. al, 2001) or a high-resolution engineering seismic survey would give more precise data about the depth and size of the cave. Unfortunately, these methods are much more expensive and time-consuming. Despite the use of only one geophysical method, information about voids and karst that affect the investigated limestones gave a more comprehensive picture for further exploration of the area of the closed quarry. Use of only one method always provides ambiguous results. However, precise measurements and thought-out profiles lines, good acquisition parameters, and optimal processing of raw data minimize the impact of the lack of a second method.

\section{ACKNOWLEDGEMENTS}

We express a special thanks to the mayor of municipality Sitkówka-Nowiny, Mr. Stanisław Barycki, who gave permission for the publication of the results of the surveys. We would like to thank the Assoc. Prof. Sally Sutton from Colorado State University, United States, and our colleague from AGH University of Science and Technology in Krakow, Poland, Ph.D. Eng. Kamila WawrzyniakGuz for support during the writing of this paper. Additional thanks are expressed to the reviewers for their comments that helped improve the manuscript and to $\mathrm{Mr}$. Maciej Grzelak for access to the photo.

Measurements were conducted by M.Sc. Eng. Mikołaj Łyskowski under the supervision of Ph.D. Eng. Jerzy Ziętek. Presentation and analysis of the surveys results were made by M.Sc. Eng. Mikołaj Łyskowski and M.Sc. Eng. Ewelina Mazurek, who are Ph.D. students at AGH University of Science and Technology in Krakow in the Department of Geophysics.

\section{REFERENCES}

Annan, A.P., 2001, Ground Penetrating Radar Workshop Notes: Mississauga, Ontario, Sensors \& Software Inc.

Beres, M., Luetscher, M., and Olivier, R., 2001, Integration of groundpenetrating radar and microgravimetric methods to map shallow caves: Journal of Applied Geophysics, v. 46, p. 249-262. doi:10.1016/ S0926-9851(01)00042-8.

Chamberlain, A.T., Sellers, W., Proctor, C., and Coard, R., 2000, Cave detection in limestone using ground penetrating radar: Journal of Archaeological Science, v. 27, p. 957-964. doi:10.1006/jasc.1999.0525.

Doolittle, J.A., and Collins, M.E., 1998, A comparison of EM induction and GPR methods in areas of karst, Geoderma, v. 85, p. 83-102. doi:10.1016/S0016-7061(98)00012-3.

Grzelak, M., 2012, Jaskinie w regionie świętokrzyskim: Jaskinie, v. 1, no. 66 , p. $25-28$.

Karczewski, J., Ortyl, Ł., and Pasternak, M., 2011, Zarys metody georadarowej, Wydanie drugie poprawione i rozszerzone: Krakow, AGH University of Science and Technology Press, $346 \mathrm{p}$.

Kondracki, J., 2011, Geografia regionalna Polski:Warsaw, Wydawnictwo Naukowe PWN 468 p.

Łyskowski, M., and Mazurek, E., 2013. Analiza konsekwencji doboru nieodpowiedniej prędkości propagacji fali elektromagnetycznej $\mathrm{w}$ trakcie interpretacji inżynierskich pomiarów metodą georadarową (English abstract): Logistyka $2013 \mathrm{nr}$ 4, suplement: CD Logistyka nauka, p. 330-336.

MALÅ Geoscience, 2009, ProEx - Professional Explorer Control Unit. Operating Manual V. 2.0.

OYO, 1988, OYO Georadar I Manual: Tsukuba, Japan, Oyo Corporation, $50 \mathrm{p}$.

Reynolds, J.M., 1997, An Introduction to Applied and Environmental Geophysics: West Sussex, England, John Wiley \& Sons, 796 p.

SSS, 2009, Reflexw Manual, User Guide: Karlsruhe, Germany, Sandmeier Scientific Software.

Urban, J., 2007, Permian to Triassic paleokarst of the Świettokrzyskie (Holy Cross) Mts., Central Poland: Geologia (Krakow), v. 33, no. 1, p. $5-50$.

Xu, Xingxin, Zeng, Qiaosong, Li, Dong, Wu, Jin, Wu, Xiangan, and Shen, Jinyin, 2010, GPR detection of several common subsurface voids inside dikes and dams: Engineering Geology, v. 111, p. 31-42. doi:10.1016/j.enggeo.2009.12.001. 